\title{
DIÁLOGO VIVIDO COMO CUIDADO HUMANIZADO NO PROCESSO EDUCATIVO DE ENFERMAGEM
}

\author{
THE EXPERIENCE OF DIALOG AS A MEANS OF HUMANIZED CARE IN THE EDUCATIONAL \\ NURSING PROCESS
}

\author{
DIÁLOGO VIVIDO COMO CUIDADO HUMANIZADO EN EL PROCESO EDUCATIVO DE \\ ENFERMERÍA
}

Autora: Joseani Pichinin Paini

Orientadora: Mercedes Trentini

\begin{abstract}
Este trabalho trata de uma pesquisa convergente assistencial focalizando o diálogo vivido como cuidado humanizado no processo educativo de enfermagem, junto a acadêmicos de enfermagem da Universidade Regional Integrada - URI Campus de Erechim e pacientes de uma Clinica Médica do Hospital de Caridade de Erechim. Teve o objetivo de mediar uma visão humanística no processo educativo de fundamentos de enfermagem no curso de graduação, tendo como referencial teórico a "Teoria da prática humanística de Paterson \& Zderad", onde a presença, o encontro, o relacionamento, o chamado e a resposta estiveram presentes durante todo o desenvolvimento do trabalho. O processo utilizado na Teoria Humanística de Paterson e Zderad possui as seguintes fases: preparação para a enfermeira que é o conhecedor para conhecer; a enfermeira conhecendo o outro pela intuição; conhecimento científico que a enfermeira tem do outro; a enfermeira que, de modo complementar, sintetiza os outros conhecidos; a seqüência, no interior da enfermeira, dos vários ao único paradoxal. Analisando os dados, podemos considerar que o trabalho mediou uma visão humanística no processo educativo de fundamentos de enfermagem no curso de graduação, através da introdução de novos meios para o cuidar, como também uma visão diferente do que é um diálogo vivido como cuidado humanizado para os acadêmicos de enfermagem, supervisora e, principalmente, para os pacientes que, juntamente com o grupo vivenciaram este cuidar.
\end{abstract}

\section{SIGNIFICADO CULTURAL DO CUIDADO HUMANIZADO EM UNIDADE DE TERAPIA INTENSIVA}

\author{
THE CULTURAL MEANING OF HUMANIZED CARE IN THE INTENSIVE CARE UNIT
}

\section{SIGNIFICADO CULTURAL DEL CUIDADO HUMANIZADO EN UNIDAD DE TERAPIA INTENSIVA}

Autora: Vanessa da Silva Carvalho Vila Orientadora: Lídia Aparecida Rossi

O presente estudo teve o objetivo de compreender o significado cultural do cuidado humanizado, na perspectiva de equipe de enfermagem que atua na UTI do Hospital das Clínicas da Universidade Federal de Goiás. Os dados foram coletados utilizando-se o método etnográfico e interpretados de acordo com os conceitos propostos por Arthur Kleinman, em seu Modelo Explicativo de Enfermidade. Na coleta de dados, foram realizadas observações-participantes e entrevistas semiestruturadas com enfermeiros, técnicos e auxiliares de enfermagem em seu ambiente de trabalho. Os dados foram coletados e analisados concomitantemente, seguindo as etapas de codificação, categorização, interpretação e identificação dos temas culturais. Com a análise dos dados, emergiram três categorias principais que deram sentido ao significado do cuidado humanizado na UTI: Cuidado Humanizado - amar ao próximo como a si mesmo; O Cuidado Humanizado - não está presente como deveria estar; Estresse e Sofrimento: é preciso cuidar de quem cuida. O tema cultural que emergiu foi: O Cuidado Humanizado: muito falado e pouco vivido. Este tema desvela a realidade do processo de cuidar em terapia intensiva, que envolve uma equipe de enfermagem que tem um conceito de humanização sintetizando na expressão: amar ao próximo como a si mesmo, mas que na prática, não revela este pensamento tão profundo. Ao mencionarem o significado cultural do cuidado humanizado, os informantes apresentaram duas perspectivas: a realidade da prática na UTI - "o vivido" - e o ideal do cuidado humanizado - "o falado". Nessas perspectivas, do ponto de vista do profissional de enfermagem, a realidade enquanto processo, ou seja, mau funcionamento interno do corpo, má adaptação ao processo biológico, que corresponde ao modelo biomédico. Ao apresentarem o conceito ideal de cuidado humanizado, os informantes se colocam no lugar do paciente e da família, assumindo a definição da doença enquanto enfermidade, que corresponde, além do mau funcionamento do organismo, à maneira como a pessoa doente, a família e seu meio consideram, rotulam, explicam e avaliam a doença. Portanto, não é meramente um estado de sofrimento, mas também uma realidade sócio-cultural. 